\title{
A PRESENÇA DE MARTINHO DE BRAGA NO MOSTEIRO DE SAN MILLÁN DE LA COGOLLA
}

\author{
Leila Rodrigues Roedel \\ Andréia Cristina Lopes Frazāo da Silva ${ }^{1 / 2}$
}

SINTESE - No presente artigo, interessa-nos apontar algumas possibilidades acerca da presença, no século X, da obra Formula Vitae Honestae, escrita por Martinho de Braga, que viveu na Galiza no século VI, na biblioteca de San Millán de la Cogolla, mosteiro localizado em La Rioja. De acordo com nossas conclusões, ainda parciais, vinculamos tal presença à identificaçăo dos dois momentos históricos, o da Galiza no século VI e por La Rioja no X, marcados pela reorganização eclesiástica e monárquica.

\begin{abstract}
In this article the interest of the authors is to point out some possibilities about the presence in the far tenth century of the work entitled Formula Vitae Honestae, written by Martin of Braga four centuries ago and kept in the library of San Millán de la Cogolla, a monastery at La Rioja. According to the partial conclusions of the authors such a presence is connected with the identification of both historical moments in the quoted centuries, namely the ecclesiastical and monarchical reorganization.
\end{abstract}

A cultura intelectual, durante a Idade Média, baseava-se, sobretudo, em livros. Como assinala Domínguez Caparrós, "[...] la Edad Media es una época en que la ciencia es una ciencia de libros [...]".' Logo, torna-se imprescindivel, para um maior conhecimento do mundo medieval, o estudo destes, bem como da sua transmissão e circulação.

Os livros foram, especialmente durante a Alta Idade Média, o mais importante veículo intelectual. Sem dúvida existiam escolas - episcopais, monásticas, paroquias - porém, todo o seu programa de ensino partia dos livros. Através destes o saber antigo, as doutrinas e regras religiosas, assim como inúmeras outras importantes informações, eram transmitidas. ${ }^{2}$

Professoras da Área de História Medieval do Departamento de História e coordenadoras do Programa de Estudos Medievais da UFRJ.

1 DOMÍNGUEZ CAPARRÓS, José. Origenes del discurso critico. Teorias antiguas y medievales sobre la interpretación. Madrid: Gredos, 1993. p. 175.

2 DIAZ Y DIAZ, Manuel C. Libros y librerías en La Rioja Altomedieval. 2. ed. Logroño: Instituto de Estudios Riojanos, 1991. p. 16. 
Contudo, os livros medievais, ao serem transmitidos, acabaram sofrendo remanejamentos. Muitos copistas prolongavam, diminuiam ou até incluiam comentários nos textos. Essas intervenções, longe de serem obstáculos para o estudo das produções literárias medievais, formam um relevante conjunto de informações sobre os processos de difusão cultural durante a Idade Média. ${ }^{3}$

Como assinala Aguadé Nieto, a passagem de um elemento cultural de uma sociedade à outra - e completaríamos com de um tempo a outro - acarreta sempre, em diversos graus, uma modificação dos mesmos, já que este processo implica ao menos dois outros: uma seleção e uma remodelação, segundo a cultura que os recebe.

Assim, não só o estudo dos processos de elaboração dos livros, à luz de seu contexto histórico, tornam-se indispensáveis para o estudo cultural da Idade Média, mas também os processos de difusão e transmissão dos textos, bem como 0 estudo material dos manuscritos que os contém.

O presente artigo pretende ser uma primeira aproximação ao tema. Trata-se de um estudo de caso. Interessa-nos apontar algumas possibilidades acerca da presença, no século X, da obra Formula Vitae Honestae, escrita por Martinho de Braga, que viveu no século VI, na biblioteca de San Millán de la Cogolla, mosteiro localizado em La Rioja, na Península Ibérica. ${ }^{5}$

Este recorte temático repousa, particularmente, em duas questões: Em primeiro lugar, no fato de Martinho de Braga ter sido um dos mais importantes e produtivos intelectuais do início da Idade Média, mas ainda ser pouco conhecido e estudado. Em segundo lugar, privilegiamos o estudo de uma biblioteca monástica riojana, não só porque constatamos a presença, ali, da obra do Bracarense, mas porque a vida monástica nesta região ocupou um papel destacado nos primeiros séculos de expansão e reorganização cristã das antigas terras muçulmanas reconquistadas.

3 Sobre esta questão ver GAULIN, Jean-Louis. L'ascése du texte ou le retour aux sources. In: BOUTIER, Jean et JULIA, Dominique. Passés recomposés. Champs et chantiers de l' Histoire. Paris: Antrement, 1995.

- AGUÁDÉ NIETO, Santiago. Libro y cultura italianos en la corona de Castilla durante la Edad Media. Alcalá de Henares: Universidade de Alcalá de Henares, 1992. p. 14.

s Denomina-se La Rioja a uma pequena região, com cerca de $5.000 \mathrm{Km} 2$, localizada no centro-norte da Peninsula Ibérica. Durante a Idade Média esta regiäo foi chamada por diversos nomes. Ainda é incerta a etimologia do nome La Rioja. Para alguns provém da expressão rivo de Ogga, surgida no século XI, designando somente o vale do rio Oja. Outros crêem que o nome deriva da cor da terra ou de seus habitantes. Há ainda uma hipótese de que o termo venha do vasco evrioguía, que significa terra do pão, ou que esteja relacionada aos ruccones. $O$ termo Rioija - Rioixa figura pela primeira vez no Fuero de Miranda, de 1099. O nome La Rioja para toda a regiảo, tal qual conhecemos hoje, foi-se afirmando na segunda metade do século XIII. Esta confusão quanto a denominação da região explica-se pelas constantes disputas, durante a Idade Média, pelo seu controle por muçulmanos e cristảos e desses últimos entre si. Quanto aos limites geográficos de La Rioja medieval, seguimos os propostos por Lama. Segundo este autor, esta região compreendia: "(...) ambas orillas del Ebro, desde la desembocadura del Bayas en Miranda, hasta del Alhama en Alfaro; desde las sierras de Cantabria, La Población y Codés, hasta las de Cameros, con el limite de sus picos, San Lorenzo, Piqueras, Oncala y las proximidades del Moncayo en Cervera, Agreda y Fitero. LAMA, I. R.R. (org.). Colección Diplomática Medieval de La Rioja. Logroño: Instituto de Estudios Riojanos, 1979, v 1. p.8. 
Dividimos o artigo em três subitens. No primeiro, faremos uma apresentação de Martinho de Braga e de sua produção literária. No segundo, trataremos do papel do Mosteiro de San Millán de la Cogolla na vida riojana no século X. Por fim, deter-nos-emos no estudo material dos manuscritos e do papel das obras de Martinho de Braga nos mosteiros de La Rioja.

\section{Martinho de Braga e sua inserção intelectual na Galiza em meados do século VI}

A contribuição intelectual de Martinho para o seu tempo se manifestou em variadas frentes e de certa forma pode, de uma maneira ou de outra, ser constatada em todas as atividades que desenvolveu na Galiza. Esta, todavia, se relacionou, invariavelmente com a reorganização e fortalecimento da Igreja na região e pode ser verificada, sobretudo, na sua atuação como fundador de mosteiros, na redação de suas obras e no trabalho de cristianização das populações do reino.

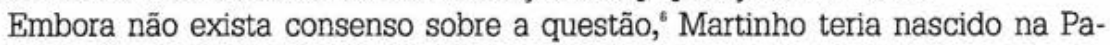
nônia, antiga provincia romana, entre os anos de 518 e 525 , e falecido em 579 . Antes de chegar à Galiza teria empreendido outras viagens, não tendo, pois, vindo direto da Panônia para o noroeste peninsular. Ainda que destas viagens existam apenas breves referências nas fontes, a realização destas assumiu relevante papel na vida de Martinho, permitindo não só aquisição de conhecimentos, mas também de material que viria a ser por ele utilizado posteriormente na Galiza. ${ }^{\text {' }}$

Martinho teria percorrido por anos as provincias orientais nas quais assimilara o grego, entre outros aspectos da sua formação helenística. Em suas viagens teria ainda completado a sua formação monástica, provavelmente adquirida na Terra Santa. É possivel que nosso autor tenha estado também no Egito," bem como na Itália,' região na qual teria realizado seus estudos dentro dos moldes latinos.

- Cf., entre outros: MADOZ, Jose. Una nueva recensión del "De Correctione Rusticorum" de Martín de Braga. Estudios Eclesiasticos, Madrid, n. 19, p. 335-353, 1945. p. 335; COSTA, Avelino de Jesus. S. Martinho de Dume. XIV Centenário da sua chegada à Peninsula. Bracara Augusta, Braga, n. 2, p. $288-325,1950$. p. 288; FERNÁNDEZ ALONSO, Justo. Martino, vescovo di Dume. In: Biblioteca Sanctorum. Roma: Instituto Giovanni XXII, 1967. p. 1230-1232. p. 1230.

O material para a organização dos Capitula Martini, procedente de concílios orientais, africanos, além de espanhóis são, certamente, assim como o texto que deu origem à tradução dos Sententiae Patrum Aegyptiorum, indicações da passagem de Martínho pelo Oriente. Cf., entre outros: MARTÍNEZ DIEZ, Gonzalo. La Coleccion Canónica de la Iglesia Sueva. Los Capitula Martini. Bracara Augusta, Braga, n. 21, p. 224-243, 1967; —— Los Concilios suevos de Braga en las colecciones canónicas de los siglos VI-XII. In: O Concilio de Braga e a Função da Legislaçăo Particular da Igreja. Atas da XIV Semana Internacional de Direito Canônico. Braga, 1975. p. 93-105. p. 98-100; FREIRE, J. Geraldes. Os "Apophthegmata Patrum" no mosteiro de Dume. Bracara Augusta, Braga, n. 21, p. 298-308, 1967. Em especial, cf.: p. 299-300.

" OLIVEIRA, Miguel de. São Martinho de Dume e a Conversão dos Suevos. Lumen, Lisboa, v. 14, p. 636-647, 1950. p. 644.

Cf.: PEREZ DE URBEL, Justo. Las Letras en la España Visigoda. In: MENENDEZ PIDAL, R. (dir.) Historia de España. España Visigoda. 2. ed. Madrid: Espasa-Calpe, 1963. v. 3. p. 447; FREIRE, J. Geraldes. Martini di Braga. Vita. Opera. Azione Monastica. In: Dizionario degli Istituti di Perfezione. Roma: Paoline,1978. p. 1031; LINAGE CONDE, A. San Martin de Braga en el Monacato Prebenedictino Hispano. Evocación Martiniana en el Centenario de San Benito. Nova et Vetera, Zamora, n. 11, Ene/jun, p. 307-321, 1981. p. 309. 
Ao chegar à Galiza, por volta de 550, Martinho era, sem dúvida, recorda Fontán, ${ }^{, 0}$ um homem culto para os padrões da época. Sua autoridade intelectual pode, certamente, ser ratificada na sua produção. Esta, conforme sublinham alguns estudiosos," demonstra claramente o conhecimento de autores como Platão, Aristóteles, Virgilio, Sêneca e Santo Agostinho. Vale ressaltar que o reconhecimento da sua erudição se baseia, não apenas na sua produção e na possível trajetória através dos centros culturais, anteriormente mencionados, mas igualmente nos elogios a seu respeito que fazem alguns dos seus contemporâneos, como For-

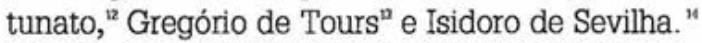

É bem verdade que o fato de ter sido elogiado pelos seus contemporâneos não se constitui como dado suficiente para que venhamos a atribuir um lugar de destaque absoluto para a bagagem intelectual do nosso autor. Precisamos, contudo, reconhecer que, na Galiza, inegavelmente, atuou como não houve outro em sua época. Na verdade, não existiram escritores no reino Suevo antes de Martinho. Aliás, verificamos que a inexistência de personalidades da sua envergadura é uma realidade para toda a história desse reino. Referimo-nos não à impossibilidade de acesso a uma bagagem intelectual semelhante à sua, mas à constatação de que ninguém fizera uso dela, como Martinho. Isto é, no interior do Reino Suevo, colocou-a a serviço da Igreja galaica.

Porém, há que se ter o cuidado no sentido de evitar legar a Martinho uma aura que o torne por demais especial. Na verdade, fora um homem culto sim, mas sua formação se fizera dentro dos parâmetros da cultura clássica, ${ }^{1,}$ acessivel, portanto, no seu momento histórico, a outros homens de um determinado segmento social. Seu destaque advém, pois, da utilização dos seus conhecimentos, seja na esfera teórica, através da redação de obras, seja no campo prático, como na participação de concilios, em prol da reorganização e fortalecimento da Igreja na Galiza.

10 FONTÁN, Antonio. Martín de Braga, un Testigo de la Tradición Clásica y Cristiana. Anuario de Estudios Medievales. Barcelona, v. 9, p. 331-341, 1974/1979. Bm especial, cf.: p. 332.

" FERREIRA, J. Augusto. Fastos Episcopais da Igreja Primacial de Braga. (sec. III-XX). Braga: Mitra Bracarense, 1928. v. 1. p. 76; MADOZ, Jose. Segundo Decenio de Estudios sobre Patrística Española (1941-1950). Madrid, 1951. p. 89; BANNIARD, Michel. Normes culturelles et realisme langagier en Galice au VI siecle: Les Choix de Martin de Braga. In: Concilio III de Toledo. XIV Centenário. 589-1989. Toledo: Arzobispado de Toledo, 1991. p. 667-670; VELAZZQUEZ SORIANO, Isabel. Ambitos y ambientes de la cultura escrita en Hispania (s. VI): De Martin de Braga a Leandro de Sevilla. Studia Ephemeridis Augustinianum, Roma, n. 46, p. 329-351, 1994. p. 339; 341.

12 FORTUNATUS, V. Opera Omnia. In: Patrologiae. Cursus Completus. Serie Latina. ed. J. P. Migne. Paris: Garnier, 1862. v. 88, Lib. 5, 1-2. p. 180.

- GREGOIRE DE TOURS. Histoire des Francs. Traduite du latin par Robert Latouche. Paris: Les Belles Lettres, 1996. Livre 5, 37. p. 300.

4 ISIDORO DE SEVILLA. Historia de los Godos, Vándalos y Suevos. Estudio, edición critica y traducción de Cristobal Rodriguez Alonso. León: Caja de Ahorros y Monte de Piedad de León y El Archivo Histórico Diocesano de León, 1975. cap. 91 . p. 319 (red. larga).

15 Sobre a formaçāo clássíca de Martinho, entre outros, cf.: RICHÉ, Pierre. Éducation et Culture dan l'Occident Barbare VI'-VIII siécles. Paris: Seuil, 1962. p. 347-348; FERREIRO, Alberto. Early Medieval Missionary Tatics: The Example of Martin and Caesarius. Studia Historica. Historia Antigua, Salamanca, v. 6, p. 226-238, 1988. p. 236-237; FONTÁN, Antonio. Martín de Braga, un Testigo de la Tradición Clásica y Cristiana. op. cit., p. 335. 
Ao chegar à Galiza, Martinho não tardou a fundar na localidade de Dume, próxima de Braga, ${ }^{16}$ o primeiro de uma série de mosteiros que passariam a existir na região. Tal mosteiro ocupou, rapidamente, no seio da província eclesiástica, posição oficial de destaque. $\mathrm{O}$ abade dumiense assumiria, a partir de então, uma espécie de presidência de uma federação de mosteiros todos ligados, em posição de subordinação, a Dume."

A quantidade de mosteiros fundados por Martinho, contudo, não é o mais relevante na sua ação monástica, mas sim o papel que tais fundações assumiram no processo de reorganização e fortalecimento da Igreja. Os problemas relacionados à ortodoxia, bem como as dificuldades existentes no seio da Igreja no que se refere à precária formação dos clérigos galaicos demandavam solução. Dessa forma, a valorização dos estudos presente na proposta monástica martiniana, já identificada com o modelo beneditino, não obstante se relacionasse com sua formação intelectual e principalmente com sua herança oriental," não the pode ser exclusivamente creditada. A importância de tais mosteiros consiste, pois, exatamente na ênfase em que neles recebeu tal formação, assim como no papel que assumiram de núcleos de propagação da Catolicismo.

Assim, os autores" que mencionam a fundação de Dume, em geral, apontam o seu papel de centro cultural e religioso. Dume se constituiu inegavelmente em importante foco de difusão da cultura cristã. Tal importância advém não da provável aquisição por parte dos clérigos de uma considerável bagagem intelectual em si, mas pela possibilidade de que estes, através do conhecimento, colaborassem no cultivo e divulgação do catolicismo, participando, assim, do processo de reorganização e fortalecimento da Igreja.

Em Dume, Martinho, entre outros aspectos, reuniu e/ou sistematizou as informações necessárias para a maioria das obras que viria a escrever. Através da redação destas obras pôde contribuir nos mais diversos campos, já que, ao escrever sobre múltiplas temáticas, invariavelmente, o seu estimulo correspondeu a

16 Embora não haja nas fontes indicaçōes sobre a cronologia dessa fundação, sabemos que se tornou bispo em 556, e que, na ocasiâo, como lembra Avelino Costa já era religioso do referido mosteiro. Cf.: COSTA, Avelino de Jesus. op. cit., p. 295.

- ORLANDIS, Jose. Las Congregaciones Monásticas en la Tradición Suevo-Gótica. Anuanio de Estudios Medievales, Barcelona, n.1, p. 97-119, 1964. p. 108.

Cf., entre outros: ANGELES GALINO, Maria. Historia de la Educación. Edades Antigua y Media. Madrid: Gredos, 1960. p. 422; LINAGE CONDE, Antonio. En tomo a la Regula Monachorum y a sus Relaciones con otras Reglas Monásticas. Bracara Augusta, Braga, v. 21, p. 123-163, 1967. p. 129.

19 Cf., entre outros: PINA, A. Ambrósio. A Cultura Greco-Latina nos mosteiros de Dume e de S. Salvador de Montélios em Braga. Lumen, Lisboa, n. 31, p. 215-219, 1967. p. 218; DIAZ Y DÍAZ, Manuel C. Martin de Braga (Saint). In: Dictionnaire de Spiritualité. Ascétique et Mistique Doctrine et Histoire. Paris: Beauchesne, 1980. v. 10. p. p. 678; RICHÉ, Pierre. Ecoles et enseignement dans le Haut Moyen Age. Paris: Picard, 1989. p. 33; GOMES, Manuel Jorge da Silva. S. Martinho de Dume: a sua ação litúrgico-pastoral. Actas do Congresso Internacional do IX Centenário de Dedicação da Sé de Braga. Braga, 1990. v. 3. p. 157-166. p. 158; FERREIRO, Alberto. The Missionary Labors of St. Martin of Braga in 6th Century Galicia. Studia Monastica, Barcelona, v. 23, n. 1, p. 11 26, 1981. p. 18; FONTÁN, Antonio. Martín de Braga, un Testigo de la Tradición Clásica y Cristiana. op. cit., p. 332. 
uma demanda constituida a partir de anseios e preocupações presentes no meio eclesiástico. ${ }^{\nsim}$

Martinho escreveu um conjunto de obras, aparentemente, pouco uniforme. Se analisarmos seus escritos buscando um ponto de convergência comum a todos eles, seja no estilo ou temática enfocados, não encontraremos tal vinculação, o que, naturalmente, não implica na afirmação de que não exista. $O$ elo que permite tal unidade se expressa, portanto, em um outro plano. Este só pode ser percebido se analisarmos o referido corpus, tendo como pressuposto básico o fato de que Martinho direcionou a sua produção no sentido de que a mesma estivesse em consonância com as prioridades eleitas pela Igreja na região.

Dessa forma, constatamos que, apesar da multiplicidade de questões enfocadas, das diferentes propostas presentes e da heterogeneidade do seu público alvo, suas obras possuíam em comum o fato de estarem inseridas no processo de reorganização e fortalecimento da Igreja. Considerando que tal processo possuiu uma ampla diversidade de possibilidades de ação, compreende-se, pois, aquela suposta carência de uniformidade presente no conjunto de obras escritas por Martinho, anteriormente mencionada.

Todavia, a partir de uma elaboração artificial, poderíamos uni-las em quatro conjuntos de acordo com algumas das suas características. Assim, podemos classificar tais obras como morais, ascéticas, canônicas e outras.

\section{Obras morais}

Formula Vitae Honestae foi certamente a mais conhecida obra de Martinho ao longo da Idade Média. Devido a sua temática de ordem moral e a sua presença junto a outros escritos de Sêneca, ${ }^{\text {n }}$ acreditou-se durante muito tempo que tal obra era produto do filósofo cordovês.

A Formula Vitae Honestae, conforme o título fornecido pelo próprio autor, apresenta-se como um texto que tem como fio condutor básico a idéia de fornecer indicações a partir das quais poder-se-ia alcançar uma forma de vida correta. ${ }^{2}$ Dedicada ao rei Miro, tal obra revela-nos, contudo, nas suas entrelinhas algo mais. Referimo-nos ao desejo de que esta veiculasse elementos fundamentais para a apresentação de um determinado modelo de comportamento para o monarca, considerado pelos eclesiásticos como ideal.

Item De Superbia, Pro Repellenda Jactantia, Exhortatio Humilitatis. Embora dedicado ao monarca, o conjunto composto por essas três obras se diferencia em

œ Há que se destacar que sua contribuição como escritor se toma ainda mais relevante se observarmos que não há nenhum outro registro da existência na regiảo, seja no âmbito da Igreja, ou não, de outros escritores, excetuando-se Pascásio, do qual sabemos apenas que realizou uma única tradução. Cf.: FREIRE, J. Geraldes. Os "Apophthegmata Patrum" no mosteiro de Dume. op. cit., p. 301.

${ }^{21}$ BARLOW, Claude W. Formula Vitae Honestae - Prolegomena. In: MARTINI EPISCOPI BRACARENSIS. Opera Omnia. Edidit Claude W. Barlow. New Haven: The American Academy in Rome, 1950. Paris, Bibliothèque Nationale, Lat., 2772 (P). p. 213.

a MARTIN DE BRAGA. Obras Completas. Versión castellana, edición y notas por Ursicino Dominguez del Val. Madrid: Fundación Universitaria Bspañola, 1990. Formula de Vida Honesta. p. 157163. 
alguns aspectos da Formula Vitae Honestae. A trilogia em questão recebeu um enfoque diverso daquele que identificara Martinho com o estoicismo. Assim, apesar do bispo bracarense não ter se afastado das questões morais, imprimiu-lhes um outro tom, ou seja, concedeu às virtudes, antes tratadas só como humanas, um caráter explicitamente cristão. Nesse sentido, abundam as menções às Sagradas Escrituras existentes nesta triade. ${ }^{z}$

De Ira responde à solicitação de orientação do bispo de Orense, Vitimiro. Escrita, certamente, após o II Concilio de Braga, insere-se entre as obras que o Bracarense dedicou a membros do episcopado local. Apesar de De Ira, conforme indicam vários estudiosos, ${ }^{2}$ ser tributária incontestável da obra de Sêneca, não existe entre os dois escritos uma relação totalmente servil. ${ }^{\text {}}$

Independente do tipo de vínculo existente entre o De Ira martiniano e Sêneca, a importância desse escrito é inegável. Seu mérito decorre, sobretudo, da oportunidade que nos proporciona de identificar mais uma temática em pauta na conjuntura de reorganização e fortalecimento da Igreja, qual seja: a busca de um comportamento humano equilibrado e adequado, segundo princípios prezados pelo Cristianismo.

\section{Obras ascéticas}

Aegyptiorum patrum sententiae ${ }^{\star}$ foi, segundo Fontán, ${ }^{n}$ a primeira obra escrita por Martinho. Trata-se, na verdade, de uma tradução, com adaptações, de um manuscrito grego, contendo vários apotegmas. ${ }^{~}$ Elaborada com o objetivo de servir aos mosteiros fundados na Galiza, como uma espécie de regra, esta obra possui uma síntese da sabedoria monástica oriental. São 110 sentenças abordando as mais variadas temáticas.

De Correctione Rusticorum ${ }^{2}$ é certamente uma das mais importantes obras do nosso bispo. Inserida no processo de reorganização e fortalecimento da Igreja, vinculou-se, particularmente, ao esforço de cristianização das populações que

2 São seis referências presentes na primeira obra, oito na segunda e dezesseis na terceira. MARTIN DE BRAGA. Obras Completas. op. cit., p. 73-91.

27 Cf., entre outros: SOUSA, Manuel Ferreira de. Notas, Inéditos e Documentos. De Ira. Revista Portuguesa de Filosofia. v. 6, p. 388-397, 1950; FONTÁN, Antonio. Anotaciones criticas al texto del Martini Bracarensis Tractatus de Ira. Emerita, n. 18, p. 377-380, 1950; ALBERTO, Paulo Farmhouse. Martinho de Braga: Atechnon ou technikon. Euphorosyne, v. 19, p. 175-200, 1991. p. 195-197; MADOZ, Jose. Segundo Decenio de Estudios sobre Patristica Española (1941-1950). op. cit., p. 91. Cf., entre outros: BARBOSA, A. de Miranda. O senequismo medieval e o corpus martinianum. Biblos, v. 41, p. 181-191, 1965. p. 185; DOMINGUEZ DEL VAL, Ursicino. Introducción. In: MARTIN DE BRAGA. Obras Completas. op. cit., p. 23.

* MARTIN DE BRAGA. Obras Completas. op. cit. Sentencias de los Padres Egipcios. p. 61-72.

FONTÁN, Antonio. Martín de Braga: Proyección Histórica de su Persona y su obra. In: Humanismo Romano. Barcelona: Planeta, 1974. p. 197.

* O monaquismo permitiu, segundo Geraldes Freire, a expansão deste gênero literário na literatura cristã a partir dos séculos V e VI. Cf.: FREIRE, J. Geraldes. Os "Apophthegmata Patrum" no mosteiro de Dume. op. cit., p. 299-300.

\% MARTIN DE BRAGA. op. cit., 145-153. 
habitavam as áreas nurais da Galiza. ${ }^{\text {A }}$ A reprodução desta obra durante a Idade Média possibilitou a sua conservação em uma dúzia de manuscritos, e teria influenciado vánias obras posteriores." A utilização de uma linguagem e estilo simples se apresenta como um elemento de destaque no De Correctione Rusticorum. Tal característica, ao que indicam as palavras do próprio Martinho, ${ }^{\text {n }}$ deve ser observada como uma decisão e não mero acaso.

\section{Obra canônica}

Identificamos neste grupo os Capitula Martini. ${ }^{\text {n }}$ Tal escrito foi anexado como complemento às Atas do II Concilio bracarense, ${ }^{x}$ produzido, portanto, após o ano de 572. Composta por oitenta e quatro capitulos, esta obra é uma coletânea de antigos cânones da Igreja. Entre estes, estão presentes cânones de concilios orientais, africanos e do I de Toledo. Apesar de se tratar de uma tradução, Martinho buscou retocar, ampliar, enfim, adaptar alguns dos cânones ali contidos à realidade local.

\section{Outras obras}

De Trina Mersione ${ }^{3}$ Este escrito foi concebido como parte da reorganização litúrgica empreendida na regiäo. Esta, ao se ocupar da definição concernente a detalhes da cerimônia de batismo, enfatizou a necessidade de que as três pessoas da Santíssima Trindade fossem mencionadas. ${ }^{*}$

3 Cf., entre outros: MCKENNA, Stephen. Paganism and Pagan survivals in Spain up to the fall of the Visigothic Kingdom. Washington: The Catholic University of America, 1938. p. 83; GOMES, Manuel Jorge da Silva. op. cit., p. 162.

n Segundo os principais autores que se dedicam ao estudo da obra De Correctione Rusticorum, esta teria influenciado diretamente autores como Elígio de Noyon (588-659) no seu tratado De supremo iudicio; Pirminio de Reichenau (morto em 753), na sua obra Scarapsus de singulis libris canonicis e o anglo-saxäo Aelfrico em seu sermão escrito em torno do ano 1000, De falsis diis. Cf.: BARLOW, Claude W. . De Correctione Rusticorum - Prolegomena. In: MARTINI EPISCOPI BRACARENSIS. op. cit., p. 165-168; MCKENNA, Stephen. op. cit., p. 86-87; MADOZ, Jose. Una nueva recensión del "De Correctione Rusticorum" de Martín de Braga. op. cit., p. 337; MACIEL, Manuel Justino Pinheiro. O "De Correctione Rusticorum". Bracara Augusta, Braga, v. 34, p. 485-561, 1980. p. 525526; DOMINGUEZ DEL VAL, Ursicino. Introducción. In: MARTIN DE BRAGA. Obras Completas. op. cit., p. 27; Introducción. In: MARTíN DE BRAGA. Sermon contra las Superticiones Rurales. Texto revisado y traducucion de Rosario Jove Clols. Barcelona: Albir, 1981p. 14-15. MARTIN DE BRAGA. op. cit., Sobre Instrucción de los Rústicos. p. 145.

33 Embora as Atas dos concilios bracarenses possam ser incluídas nesta designação por resultarem dos concilios, devemos observá-las, sobretudo, sob o status de obra coletiva. Dessa forma, năo sendo de autoria exclusiva de Martinho, optamos por não nos determos nas mesmas. Concilios Visigóticos e Hispano-Romanos. Edición Jose Vives. Madrid: CSIC. Instituto Enrique Florez, 1963. Capitula Martini. p. 85-106.

35 MARTIN DE BRAGA. op. cit., Sobre la Triple Inmersión. p. 167-169.

* Nesta obra Martinho recordou a orientação fornecida pelo papa Vigilio e pela tradição antiga e apostólica. Cf., entre outros: MADOZ, Jose. Arrianismo y Priscilianismo en Galicia. Bracara Augusta, Braga, v. 8, n. 1/2, p. 68-86, 1957. Em especial, cf.: p. 83; VAZ, A. Luis. Liturgia de Braga. Que é? Como Nasceu e se Formou? Braga: Presença e Diálogo, 1991. p. 51-55; ROMERO-POSE, Eugenio. Transfondo Teológico del III Concilio de Toledo. In: Concilio III de Toledo. XIV Centenário. 589-1989. Toledo: Arzobispado de Toledo, 1991. p. 357-376. Em especial, cf.: p. 361-363; FER- 
In Basilicam, ${ }^{n}$ In Refectorio e Epitaphium ${ }^{x}$ refletem a formação greco-latina de Martinho, segundo a qual a composição de poesias se apresentava como um dado natural. Trata-se, praticamente, das únicas poesias, segundo Velázquez Soriano," escritas na Península no século VI.

Ao finalizar este subitem desejamos sublinhar que a atuação de Martinho e as suas obras se vinculam a uma conjuntura favorável à rediscussäo de questões pendentes no seio da Igreja galaica. Logo, justifica-se não apenas o interesse de Martinho por determinados temas, mas também a existência de uma demanda do episcopado local no mesmo sentido. Martinho, exceto pela sua formação intelectual, não era muito diferente da maioria dos homens que compunham a cúpula da Igreja na região. Logo, o Bracarense participava dos mesmos problemas e possuía, evidentemente, a mesma "visão de mundo"" que as demais autoridades eclesiásticas locais. Portanto, ao escrever, nosso autor expressou o ambiente no qual se encontrava inserido, ou seja, fazia parte de uma tendência que se orientava a partir de um certo frenesi, articulado com a reorganização das esferas disciplinar, litúrgica e doutrinal da Igreja. Sua atuação, desvelada nas referências diretas que lhe são feitas por contemporâneos, mas sobretudo, pela análise das suas obras, indica-nos que estivera em plena sintonia com os anseios, angústias e dúvidas do episcopado galaico. O Bracarense procurou, pois, enfocar na maioria das suas obras questōes discutidas pelos religiosos.

A autoridade martiniana expressa em variadas circunstâncias, tornara-o um legítimo representante do segmento episcopal local. Suas obras permitem, portanto, a observação, não apenas do reconhecimento de sua autoridade frente aos demais membros da Igreja, mas, sobretudo, são capazes de evidenciar os anseios, preocupações e pensamento, de uma maneira geral, desses religiosos. Martinho não é apenas o conselheiro, ou o homem experiente, ou o homem culto, ou o metropolitano a quem se recorre diante de dificuldades, mas é tudo isso e, principalmente, uma espécie de porta-voz das autoridades eclesiásticas locais.

\section{La Rioja e o mosteiro de San Millán de la Cogolla no século X}

"Es imposible entender a La Rioja sin sus monasterios." Como afirma Atienza, esta localidade foi, desde o periodo visigótico, um "núcleo de espiritualidad fundamental a lo largo de toda la Edad Media." Entretanto, no século X, o movimento monástico riojano possuía algumas particularidades que só podemos compreender se nos reportamos aos processos de reconquista, repovoamento, coloni-

NÁNDEZ ALONSO, Justo. La cura pastoral en la España romanovisigoda. Roma: Instituto Español de Estudios Eclesiásticos, 1955. p. 288-290.

MARTINI EPISCOPI BRACARENSIS. op. cit., In Basilicam. p. 282.

* Idem, In Refectorio. p. 283.

* Idem, ibid.

* VELAZZOUEZ SORIANO, Isabel. op. cit., p. 343.

" Cf.: GUREVITCH, Aron I. As Categorias da Cultura Medieval. Lisboa: Caminho, 1990. p. 29.

- ABAD LEÓN, F. Los monasterios riojanos. In: AAVV. Historia de La Rioja. Logroño: Instituto de Estudios Riojanos, 1982. T. 2. p. 223.

- ATIENZA, J. G. Monjes y monasterios españoles en la Edad Media. Madrid: Temas de Hoy, 1994. p. 68. 
zação e organização dos reinos hispano-cristãos do norte, em andamento neste momento, e que tanto repercutiram na história desta região.

A presença islâmica em La Rioja ocorreu a partir de 714. Segundo apontam Sáinz Ripa" e Sétien y Garcia," não houve resistência aos recém-chegados e grande parte da população hispano-visigótica buscou refúgio nas montanhas próximas. Estas áreas montanhosas permaneceram livres da dominação islâmica, visto que os muçulmanos só se estabeleceram de forma efetiva nos espaços urbanizadas do vale do Ebro, preocupando-se unicamente em fortificar os acessos aos vales dos rios da região: o Tirón, Najerilla, Iregua, Cidacos e Alhama."

Essas áreas montanhosas, de difícil acesso, tornaram-se núcleos cristãos que mantiveram vivas as tradições do cristianismo hispano-visigótico. Foram esses grupos que iniciaram, mesmo que tímida e lentamente, o movimento de presura, ainda no século IX."

Este repovoamento significou o deslocamento da população que havia se refugiado nas montanhas, em um movimento, ora coletivo ora particular, para áreas mais baixas e férteis e implicou na transferência de pequenos mosteiros e igrejas, fiéis à tradição hispano-visigótica, motivados tanto por necessidades materiais como por razōes religiosas." Tais mosteiros, apesar de muitos, eram pequenos, pobres, dispersos, instáveis, particulares ou próprios, pactualistas, familiares ou dúplices e seus membros não seguiam uma estreita regra monástica."

A expansão dos cristãos frente às áreas de ocupação muçulmana ocorreu concomitantemente à organização dos diversos reinos hispano-cristãos. A partir dos núcleos astur e cantábrico, no século VIII organizara-se o Reino Astur-leonês, ${ }^{*}$ já o reino de Pamplona teve como ponto de partida o antigo território dos vascos. Após uma política de expansão e a ação diplomática, desenvolvida no século IX,

4 SÁINZ RIPA, E. Sedes episcopales de La Rioja. Siglos IV-XIII. Logroño: Dioceses de Calahorra y La Calzada-Logroño, 1994. p. 126.

- SETIÉN Y GARCIA, J. M. La dominación musulmana en La Rioja (711-1031). In: AAVV. Historia de La Rioja. op. cit., p. 66.

- SÁINZ RIPA, B. op. cit., p.133; SETIÉN Y GARCIA, J. M. op. cit., p.52.

- Presura é o nome dado ao direito de reclamar uma terra, antes despovoadas, através de sua ocupação e exploração econômica da Península Ibérica, ocorrido de forma paralela à Reconquista militar. Sobre o termo pressura ver GUGLIELMI, N. et al. Lexico Historico del occidente medieval. Buenos Aires: Biblos, 1991, p.100-101. Sobre o movimento de pressura em La Rioja a partir do século VIII, ver: GLICK, T. F. Cristianos y musulmanes en la España Medieval (711-1250). 2 ed. Madrid: Alianza, 1993. p.116.

- FACI, J. La influencia economica, social y cultural del monacato. In: GARCIA-VILLOSLADA, R. (dir.) Historia de la Iglesia en España. Madrid: Biblioteca de Autores Cristianos, 1982. T. 2, v. 1. p. 192-201.

- Muitos autores atribuem estas especificidades do monacato hispano, no início da Reconquista, ao seu isolamento do restante da Europa. Contudo, recentes pesquisas vem demonstrando que sempre existiram contatos entre estes mosteiros e os cenóbios da Marca Hispânica e de além-Pirinéus, 0 que resultou em influências reciprocas. Cf.: ALVAREZ PALENZUELA, V. A. Expansión de las órdenes monásticas en España durante La Edad Media. In: IGLESIA DUARTE, J. I. (coord.). Semana de Estudios Medievales, 3, Nájera, 1992. Actas... Logroño: Instituto de Estudios Riojanos, 1993. p. $162-164$.

so RUCOUOI, Adeline. História Medieval da Peninsula Ibérica. Lisboa: Estampa, 1995. p. 133-143. 
esta região foi estruturando-se e já no início do século $\mathrm{X}$ despontou como um reino organizado, tendo Sancho Garcês I, como rei. ${ }^{51}$

A princípio do século X, os Reinos Astur-leonês e Pamplonês, ${ }^{, 2}$ unidos, conquistaram as regiōes mais ocidentais de La Rioja, passando ao controle cristão os vales dos afluentes do meio Ebro: Najerilla, Iregua, Leza. Apesar da ação conjunta de pamploneses e astur-leoneses na reconquista da região nesta etapa, o Reino Astur-leonês não se expandiu para o leste, entregando as terras conquistadas a Pamplona. Segundo Faci, ${ }^{\text {" o }}$ desinteresse por La Rioja por parte dos asturleoneses, neste momento, pode ser explicado pela política de restrição aos condes de Castela que, sem dúvida, devido a sua posição geográfica, ${ }^{\text {" }}$ seriam os mais favorecidos com as conquistas.

A presença pamplonesa nesta região foi efetiva durante cerca de 150 anos (923 - 1076). Os reis pamploneses transformaram Nájera, antiga cidade muçulmana localizada em La Rioja, na nova capital do Reino, tornando-a residência da Corte já por volta de 931 . O chamado Reino de Nájera representou para o Reino de Pamplona o início de um periodo de prosperidade econômica e de hegemonia política na Península Ibérica. ${ }^{\text {" }}$

A expansão da reconquista militar e a consolidação do domínio pamplonês em La Rioja implicaram em inúmeras transformações nesta região. Iniciou-se um processo de vasconização, principalmente no tocante à língua e patrocínios; ${ }^{60}$ chegaram à região homens provenientes do Norte, com o objetivo de repovoar e colonizar a área; foram concedidos fueros às cidades; restauraram-se caminhos e construíram-se pontes, templos e albergues, criando assim uma infra-estrutura para os que se deslocavam pela regiảo; foi cunhada a primeira moeda cristã;" iniciou-se um processo de reorganização eclesiástica, através da transferência do bispado, estruturação da rede paroquial, realização de concílios, fundação de grandes mosteiros e igrejas e prosseguiu-se com a expansão cristã em La Rioja.

51 Sobre o Reino de Pamplona ver LACARRA, J. M. Historia del Reino de Navarra en la Edad Media. Pamplona: s/ed., 1976.

62 Optamos pelo uso do termo Pamplona ao invés de Navarra visto que os os seus Reis, até meados do século XII, apresentam-se como rex in Pampilona.

FACI, J. El proceso de unificacion de la Reconquista. In: GARCIA-VILLOSLADA, R. (dir.) op. cit., p.102.

4 $\mathrm{O}$ condado de Castela encontrava-se na área mais oriental do Reino Astur-leonês, fazendo fronteira com as áreas riojanas recém conquistadas. Seus condes, apesar de certa autonomia, reconheciam o governo astur-leonês. Cf.: RUCQUOI, Adeline. op. cit., p. 140.

s Nẫo se deve confundir o Reino de Nájera com Pamplona, pois ainda que os reis de Nájera tenham procedido de uma dinastia pamplonesa, não utilizaram jamais o nome da regiáo de sua procedência como substituto ao do reino em que se estabeleceram. Além disso, o Reino de Nájera subsistiu como entidade política, mesmo após o fim do domínio pamplonês na região, como é possível desvelar pelas fórmulas de titulaçäo dos reis castelhanos nos séculos seguintes. Sobre o Reino de Nájera ver PADLLA MAYORAL, M. C. F. El Reino de Nájera (población, economía, sociedad y poder). Logroño: Instituto de Estudios Riojanos, 1991.

* ALVAR, M. El dialecto riojano. Madrid: Gredos, 1976. p. 11-13.

* Nem todos os autores concordam que em Nájera foram cunhadas as primeiras moedas cristãs. Sobre a questão ver o artigo de RODRfGUEZ LATORRE, L. E. Una ceca en el camino : la ceca de Nájera. In : IGLESIA DUARTE, J. I. (coord.) Semana de Estudios Medievales, 4, Nájera, 1993. Actas... Logroño: Instituto de Estudios Riojanos, 1994. 
Todas essas transformações são facetas dos processos de repovoamento e colonização que foram desenvolvidas em todos os reinos hispano-cristãos, com 0 objetivo de consolidar a presença cristã nas terras recém-incorporadas." Estas atividades implicavam "[...] la expansión tenaz, perseverante y laboriosa de la sociedad cristiana [...]", em meio a um ambiente de tensão, pois essas áreas estavam sujeitas tanto a constantes aceifas ${ }^{\infty}$ muçulmanas de verão, até o início do século XI, quanto aos conflitos entre os próprios reinos cristãos em organização.

Dentre as diversas faces dos processos de repovoamento e colonização em La Rioja no século X, há que se destacar a ação dos grandes mosteiros riojanos que ocuparam um papel fundamental como dirigentes das atividades econômicas, ordenadores da vida social, núcleos de produção intelectual, centros de espiritualidade, pontos estratégicos na defesa das fronteiras interiores e base para avanços territoriais posteriores, consolidando a reconquista da região e produzindo recursos para financiar novas guerras contra os mouros e vizinhos cristãos.

Logo, frente ao grande número de mosteiros pequenos, pobres e instáveis, presentes anteriormente em La Rioja, desenvolveu-se um processo de concentração monástica. Os grandes cenóbios que surgem no século X são, portanto, fruto deste movimento e representam uma remodelação em relação à vida monástica anterior."

Segundo Orlandis, ${ }^{\text {,2 }}$ este processo implicou na integração dos pequenos mosteiros e igrejas surgidos no século IX às grandes abadias, através de doações por parte de seus proprietánios, nobres e reis, já que se tratava de igrejas e mosteiros próprios. Estas doações teriam sido motivadas pelo interesse em reorganizar a vida eclesiástica, impulsionada pelos reis ibéricos, já mencionada no tocante ao reino pamplonês.

Paralelo a este processo de concentração monástica, alguns autores defendem que, como já em fins do século IX circulavam em La Rioja manuscritos com os comentários à regra de São Bento elaborados por Esmengardo, também processou-se, no século X, a introdução da observância beneditina nestas grandes abadias."

- GARCIA DE CORTÁZAR, J. A. Introducción al estudio de la sociedad altoriojana en los siglos X a XIV. Berceo, Logroño, n. 88, p. 3-29, 1975, p. 15.

ANDRÉS VALERO, S. La reconquista y repoblación en La Rioja. In: AAVV. História de La Rioja. op. cit., p. 86.

- Aceifa é o nome dado às expedições de saque organizadas pelos muçulmanos que visavam, principalmente, conter e aterrorizar os núcleos cristãos avançados de repovoamento e colonização.

* Uma das questöes que ainda se apresentam a todos os que desejam estudar o monacato riojano durante os primeiros passos da reconquista é se este mantém relação com os movimentos eremíticos e semi-eremíticos visigóticos. Acreditamos que houve uma continuação no movimento monástico, do eremitismo para o cenobitismo, nas regiöes montanhosas de La Rioja e que esta com a reconquista, repovoamento e colonizaçäo, sofreu algumas modificações, adaptando-se à nova situação histórica, particularmente a partir do século X. Sobre este debate historiográfico ver DIAZ Y DIAZ, Manuel C. op. cit., p. 97-101.

a ORLANDIS, J. Reforma Eclesiástica en los siglos XI y XII. In: —— . La iglesia en la España visigótica y medieval. Pamplona : Universidad de Navarra, 1976, p. 307-348.

a LINAGE CONDE, A Introduccion de la regla beneditina. In: GARCIA-VIILOSLADA, R. (dir.) op. cit., p. 149-171. Em um exame atento dos acervos destas bibliotecas monásticas, encontramos manuscritos com obras de todos os importantes inspiradores do monacato visigodo, com destaque 
Esses grandes mosteiros agregavam um maior número de monges; possuiam autonomia pois não eram próprios, isto é , não eram propriedades de reis, bispos ou nobres; ${ }^{m}$ exerciam jurisdição sob inúmeros outros mosteiros e igrejas que lhes eram entregues como doação, bem como usufruiram da concessão, por parte dos reis, de imunidades e privilégios. Em alguns casos, os próprios mosteiros fundavam novas igrejas.

Dentre os muitos mosteiros surgidos em La Rioja neste momento, destaca-se o de San Millán de la Cogolla, em cuja biblioteca, no século X, encontrava-se a obra Formula Vitae Honestae de Martinho de Braga.

A tradição atribui a San Millán, eremita do século VI que viveu nas montanhas riojanas, a fundação do mosteiro emilinense. Ao morrer, San Millán não chegara a formar uma comunidade monástica propriamente dita, mas teria reunido alguns seguidores, iniciando, assim, um núcleo semi-eremítico. Não há documentos que comprovem esta continuidade, mas é possivel que esta tenha ocorrido. Um grupo de eremitas que mantiveram viva a memória de San Millán, em torno a sua sepultura, poderia ter sido o núcleo básico a partir do qual se processou uma concentração monástica e que resultou no mosteiro de San Millán de la Cogolla. ${ }^{\text {" }}$

Os primeiros documentos que fazem referências diretas a este cenóbio datam do século X. ${ }^{\alpha}$ Assim sendo, seja como fruto de uma restauraçăo tardia ou decorrente da continuidade do grupo semi-eremítico fundado por San Millán, podemos atestar que, neste século, o Mosteiro de San Millán de la Cogolla já estava organizado.

Este mosteiro prosperou muito durante o século X. Sua privilegiada posição geográfica, pois encontrava-se situado entre o condado de Castela e o Reino de Pamplona, o fez alvo de favores por parte de ambos. Desta forma, mesmo quando La Rioja ainda integrava geograficamente o reino de Pamplona, o mosteiro de San Millán de la Cogolla já se achava sob forte influência castelhana. Este dado individualizou o mosteiro emilianense perante as demais casas monásticas riojanas, já que, desde o século X, gravitou entre as órbitas de influência castelhana e pamplonesa. ${ }^{\text {"I }}$

San Millán de la Cogolla, por sua riqueza e localização estratégica, foi um “[...] punto de encuentro de gentes, textos y costumbres de las distintas regio-

para Isidoro de Sevilha. Este dado nos faz inferir que ou a regra de São Bento ainda não se encontrava consolidada como única disciplina a ser seguida no século $\mathrm{X}$ ou que existia uma resistência interna à esta aceitação. Podemos pensar inclusive em facçōes favoráveis a beneditização e outras fiéis a tradição ou, até mesmo, a convivência das duas tradições. Por outro lado, $\mathrm{O}$ grande impulso ao processo de concentração monástica e beneditização em La Rioja, como em outras regiões da Península Ibérica, veio com o concilio de Coyanza e o apoio real à Reforma Eclesiástíca, reforçado ainda mais com a chegada dos cluniascenses e o impacto da reforma gregoriana. FACI, J. Estructuras sociales de los reinos cristianos (S. VIII-IX). La Iglesia Propria en España. In: GARCIA-VILLOSLADA, R. (dir.) op. cit., p. 118-139.

* GARCIA DE CORTÁZAR, J. A . El dominio del monasterio de San Millán de la Cogolla. Salamanca: Universidade Pontificia de Salamanca, 1969.

* LINAGE CONDE, A Los origenes del monacato benedictino en la Península Ibérica. León: CSIC Centro de Estudios Y Investigación São Isidoro, 1973, v. 2, p. 648.

- VARASCHIN, A. San Millán de la Cogolla : le temps du monastère ou l 'imaginaire de Gonzalo de Berceo. Cahiers de Civilisation Médiévale, Poitiers, n. 24, p. 257-267, 1981. p. 260. 
nes." Ali estabeleceram-se monges provenientes de Astúrias, Castela, dos Condados da catalunha, de além-Pirinéus e das regiões sob controle muçulmano.

Não só monges viviam ou passavam por San Millán de la Cogolla. Durante o século $\mathrm{X}$ este mosteiro foi residência episcopal. Como possuidor e organizador de inúmeras áreas produtivas, este cenóbio igualmente atraía um grande número de leigos que atuavam como agricultores, pastores e artesãos. A presença de leigos e seculares no mosteiro emilianense também se relaciona a dois outros fatores: por ser centro de peregrinação, já que ali encontrava-se o túmulo de San Millán, considerado patrono de Castela, bem como porque funcionava como local de assistência, possuindo hospitais e alojamento para os peregrinos, pobres, doentes, viajantes e necessitados em geral.

Mas de todos os elementos que caracterizaram a vida monástica emilianense, como a de outros cenóbios riojanos medievais, interessa-nos, especialmente, seu papel de destaque na história intelectual da Península Ibérica. Neste mosteiro funcionava uma escola, um scriptorium - onde eram copiados e produzidos manuscritos - e uma biblioteca. Graças aos inúmeros manuscritos conservados em San Millán de la Cogolla, descritos por Díaz y Díaz, bem como pelas listas bibliográficas transmitidas e achados arqueológicos, podemos chegar a algumas conclusões."

$\mathrm{Na}$ escola aprendia-se a ler e a escrever em Latim, bem como a dominar princípios teológicos básicos. Esstudava-se a Bíblia e os textos patrísticos, bem como a gramática antiga, com especial destaque à métrica e às técnicas relacionadas à produção de manuscritos.

Em San Millán de la Cogolla, como em outros grandes mosteiros riojanos, nos scriptorium, os manuscritos eram produzidos por verdadeiras equipes com pessoal especializado. ${ }^{\circ}$ Em sua maioria, os copistas e iluminadores eram os monges. Graças a um manuscrito produzido em San Millán de la Cogolla, ${ }^{n}$ na segunda metade do século $\mathrm{X}$, rico em notas, podemos conhecer um pouco mais do trabalho de um copista. A média de trabalho diária era de uma página copiada. Não havia qualquer incompatibilidade entre a guarda do domingo e a cópia de manuscritos. As cópias eram feitas dentro de uma certa margem de autonomia: muitos copistas incluíam ou não as notas de seu modelo, redigiam colofons ao final, incluíam glosas para auxiliar o leitor, mudavam a ordem ou introduziam elementos novos frente aos manuscritos-modelo etc.

DIAZ Y DIAZ, Manuel C, op. cit., p. 155.

* Além do trabalho de Diaz y Díaz, que contém a edição de inúmeros documentos, nos utilizamos do artigo de SLVA Y VERÁSTEGUI, S. Los monasterios riojanos y el arte de la miniatura en el Alto Medioevo. In: IGLESIA DUARTE, J. I. (coord.). Semana de Estudios Medievales, 3, Nájera, 1992. Actas... Logroño: Instituto de Estudios Riojanos, 1993. p.213 a 231, rico em reproduções de miniaturas.

* MENÉNDEZ PIDAL, Gonzalo. MENÉNDEZ PIDAL, Gonzalo. Sobre el escritorio emilianense. Boletin de la Real Academia de la Historia. Madrid, 1958. p. 9-10.

$n$ Trata-se do códice 29 da Academia de la Historia. Díaz y Díaz o descreve. Cf.: DIAZ Y DIAZ, Manuel C. op. cit., p. 147-155. 
A biblioteca emilianense não contava só com os livros produzidos ou copiados em seus scriptorium, mas também possuía livros de diversas procedências. ${ }^{n}$ Graças ao estudo material dos manuscritos, podemos constatar contatos com outros mosteiros riojanos, como San Martin de Albelda, bem como destes com outras regiões peninsulares, como Catalunha e Burgos.

Foram muitos os meios pelos quais os livros chegaram ou saíram de San Millán de la Cogolla. Através dos viajantes e peregrinos, afinal La Rioja era uma das etapas do caminho de peregrinação a Santiago de Compostela, que já atraía estrangeiros no século $\mathrm{X}^{n}$ Assim, como terra de passagem, esta região foi um espaço privilegiado na recepção e transmissão de pessoas e idéias. Não podemos nos esquecer dos repovoadores. Quando no século X os reis pamploneses estimularam a formação dos grandes mosteiros riojanos, também incentivaram a migração de monges provenientes das mais diversas regiões da península Ibérica. Muitos, ao instalarem-se nos mosteiros da região, acabaram trazendo manuscritos e/ou técnicas para confeccioná-los. Por fim, os livros também chegavam através de doações.

A partir das obras que nos foram preservadas é possível reconstruir o acervo da biblioteca de San Millán de la Cogolla no século X. Não existem profundas diferenças entre os livros presentes em cada grande abadia riojana. Estas residem principalmente naqueles textos relacionados diretamente ao Mosteiro, como as hagiografias de seus patronos. Tampouco apresentam grandes diferenças frente a outras abadias beneditinas da Europa, como o trabalho de Dalla Guardia o demonstra."

As obras presentes nesta biblioteca podem ser classificadas em cinco grupos básicos. São obras bíblicas, incluindo aí não só as Bíblias mas também comentários a textos bíblicos. Obras litúrgicas, fundamentais para os serviços religiosos. Textos de caráter histórico, tais como crônicas, hagiografias, genealogias, calendários etc..., com destaque para as obras históricas hispanas, como as de Isidoro de Sevilha, e patrísticas, como A cidade de Deus. Obras de caráter jurídico, como a Hispania e o Fuero Juzgo. E, por fim, textos de disciplina e espiritualidade monástica, como as regras de Frutuoso e Isidoro e o comentário de Esmaragdo à Regra de S. Bento. E as obras de Martinho de Braga?

Nesse ponto em particular, conforme nossa proposta evidenciada no início desse texto, reside nossa maior atenção. Assim, após consultar e comparar os manuscritos e listas de livros das bibliotecas monásticas riojanas, constatamos que existia uma obra deste autor, Martinho de Braga, presente em uma única biblioteca de La Rioja, a emilianense. Indagamos, portanto: que tipo de interesse teria

n Se encontramos um volume em uma dada biblioteca cujo conteúdo não é fruto de produção local ou cópia de algum outro já existente no local, este só pode provir de um outro manuscrito, estranho ao mosteiro, que the serviu como cópia. Comparando-os com os manuscritos preservados da mesma familia, ou através dos próprios traços incluidos pelos copistas ou iluminadores frente ao manuscrito original, é possivel reconstruir os intercâmbios de manuscritos que íniciaram-se no século IX. Sobre a circulaçăo de livros entre San Millán de la Cogolla e outras regiốes ver: DIAZ Y DIAZ, Manuel C, op. cit., p. 217-259.

$n$ GIL DEL Rf́, A El Camino de Santiago por La Rioja. In: AAVV. Historia de La Rioja. op. cit., p. 270-279.

"7 DALLA GUARDIA, D. N. Les listes médiévales de lectures manastiques. Contribution à la connaissance des anciennes bibliothèques bénédictines. Revue Benedictine, n. 2, v. 96, p. 271-326, 1986. 
permitido a existência de uma obra do bispo bracarense em um mosteiro riojano, já que os autores ali presentes eram preferencialmente escritores cujas obras foram mais comumente reproduzidas, não só no âmbito da Península Ibérica, mas de toda a Europa Ocidental, como Agostinho e Isidoro de Sevilha? Se considerarmos que naquele momento Martinho era mais popular que em épocas posteriores, dai o interesse pela sua produção naquela localidade, por que então apenas uma de suas obras esteve presente e em um único mosteiro? Acreditando que não 0 acaso, mas sim que um ou mais elementos acabaram por definir tal presença, passamos, a seguir, a discorrer sobre tal problemática.

Antes, porém, gostariamos de ressaltar, mais uma vez, que como este artigo é uma primeira abordagem ao tema, nos limitaremos a apontar e discutir possiveis explicações para as questões levantadas, sem propor uma conclusão final fechada.

\section{Martinho de Braga em San Millán de la Cogolla}

A obra Formulae Vitae Honestae, de Martinho de Braga, encontra-se em um manuscrito que reúne obras copiadas no Mosteiro de San Millán de la Cogolla, em 933, pelo escriba Jimeno, segundo dados presentes no próprio texto. ${ }^{\top}$ As primeiras páginas deste manuscrito foram perdidas, mas encontram-se preservadas, divididas em dois cadernos, as seguintes obras: no primeiro, Adversus Iovinianum e Apologeticum ad Pamacium, ambos os textos de Jerônimo; o Liber Eruditionum ou, como também é conhecido, o Formulae spiritalis intellegentiae de Euquerio de Lyon; o Pronosticon de Juliano de Toledo; no segundo, encontram-se o elenco das sedes episcopais hispanas, umas narrações sobre a Terra Santa, uma relação de personagens do Antigo Testamento e as obras Via Regia de Esmaragdo de SaintMihiel, o Liber metricus de suprascriptis virtutibus, atribuído a Alcuíno de York, parte do tratado De substantia trinitatis, de Potamio de Lisboa, ${ }^{,}$uma carta de Alcuino de York dirigida a Beato de Liébana e por fim, a obra que nos interessa, a Formulae Vitae Honestae de Martinho de Braga.

Retomemos, nesse momento, as nossas reflexões concernentes à chegada do escrito bracarense neste mosteiro. Há que se destacar que apenas um autor fez referências a esta problemática. Refirimo-nos ao filólogo Díaz e Díaz. ${ }^{n}$ De acordo com este especialista, as obras que compõem o segundo caderno do dito códice reúne textos que foram copiados de manuscritos pirenaicos. Logo, a obra de Martinho de Braga teria chegado ao mosteiro emilianense a partir de uma fonte vinda diretamente de algum cenóbio desta localidade. Sem maiores considerações, limita-se a afirmar que: “[...] la tradición de Martín de Braga se refugió en monasterios pirenaicos [...]".

Embora Díaz e Díaz não tenha se detido na questão, acreditamos que sua afirmação se relaciona com o processo de conquista muçulmana da Península Ibérica. Sabemos que as regiões hispanas mais ocidentais, incluindo aí a Galiza,

\% Trata-se do Manuscrito 1007 B, que atualmente encontra-se no Arquivo Histórico Nacional de Madrid. Cf.: DÍAZ Y DİAZ, Manuel C. op. cit., p. 111.

* Curiosamente, neste manuscrito, tal obra fora atribuida a Jerônimo.

$n$ DÍAZ Y DİAZ, Manuel C. op. cit., p. 115.

s Idem. 
local onde Martinho de Braga atuou e produziu suas obras, receberam um grande contingente de invasores muçulmanos, já no século VIII. Grupos bérberes islamizados ali se instalaram com o objetivo de colonizar a terra. ${ }^{\pi}$ Como as regiões norte-orientais da Península eram de difícil acesso, com baixas temperaturas durante a maior parte do ano, nestas localidades o número de muçuimanos estabelecidos será bem menor. Acrescentam-se às dificuldades naturais encontradas pelos invasores islâmicos, não só a pouca urbanização destas áreas, mas também o fato de que tais regiões foram, prontamente, alvo de incursões e ocupação franca. Assim, é possivel que monges galaicos, portando manuscritos com a obra do Bracarense, tenham buscado refúgio nos mosteiros pirenaicos.

Ao concordamos com a hipótese de Díaz e Díaz, não podemos, portanto, atribuir a presença da obra do Bracarense à continuidade da vida eremítica e semieremítica nas montanhas riojanas, fiéis à tradição hispano-visigótica. Ou seja, a despeito do que à primeira vista poderia parecer, o fato de os núcleos cristãos riojanos terem mantido as tradições do cristianismo hispano-visigótico, não implicou na preservação da obra de Martinho de Braga. Esses grupos de resistência cristã, situados em áreas fronteiriças com os muçulmanas, tinham como principal objetivo a subsistência. Suas dificuldades, relacionadas mais diretamente com o cotidiano, não lhes teria proporcionado qualquer estímulo no sentido de que viessem a promover atividades intelectuais que justificassem a presença, em suas incipientes bibliotecas, de obras relacionadas com outras questões diversas da sobrevivência destes pequenos cenóbios.

Pautados nas consideraçōes acima, como podemos explicar a chegada da obra De Formula Vitae Honestae em San Millán de la Cogolla? Com o avanço efetivo da reconquista militar em La Rioja e o início de uma política, por parte dos reis pamploneses, de repovoamento e colonização da região com base em grandes mosteiros, é possivel que alguns monges, provenientes dos Pirineus, tenham optado por instalar-se na região riojana, devido às vantagens oferecidas. Nesse sentido, devemos observar, portanto, duas possibilidades para explicar a chegada desta obra a San Millán de la Cogolla. Primeira, os monges que ali se estabeleceram trouxeram consigo tal obra. Segunda, a partir de uma rede de comunicação, instaurada desde então, entre as casas de origem e o atual mosteiro em la Cogolla, tais monges teriam tido acesso a esse manuscrito e o reproduzido.

Dessa forma, tendo já apresentado possíveis explicações para a chegada da obra De Formula Vitae Honestae de Martinho de Braga em San Millán de la Cogolla, vinculando-as ao século $\mathrm{X}$, acreditamos estar, igualmente, neste momento histórico as prováveis justificativas para a recepção desta obra em particular, no mosteiro emilianense. Em outras palavras, o escrito bracarense teria sido reproduzido neste mosteiro por, de uma forma ou de outra, atender expectativas, interesses e objetivos especificos desse contexto, ou seja, resultado de uma escolha deliberada.

* Por volta de 740 os bérberes acabam por abandonar essa regiāoem virtude da grande fome que devastou o centro de Península Ibérica, bem como por força da repressão exercidas pelas tropas sirias, suprimindo focos de rebelião. Cf.: RUCQUOI, Adeline. op. cit, p. 69-70. 
Nesse sentido, podemos associar tal opção a pelo menos quatro fatores que se inter-relacionam, que passamos a apresentar. Primeiro, a obra de Martinho de Braga significaria, no século $\mathrm{X}$, a retomada da identidade cristã ibérica frente a elemento hispano-muçulmano. Segundo, a memória da prosperidade material do monacato introduzido por Martinho de Braga na Galiza. Terceiro, enquanto um fundador de mosteiros, é possivel que a obra de Martinho de Braga fora copiada por apresentar principios de espiritualidade em harmonia com a vida cenobitica riojana. Quarto, La Rioja vivia, no século X, um momento de reorganização da vida eclesiástica tal qual àquele experimentado pela Igreja na Galiza a partir de meados do século VI. Quinto, da mesma forma que a Monarquia Sueva procurava, no século VI, reforçar sua legitimidade, sobretudo, frente às populações locais, a região riojana tornava-se sede de um reino cristão nascente, o de Pamplona, cuja autoridade buscava-se construir e reforçar.

Vejamos, mais atentamente, cada um desses fatores acima apontados. Martinho de Braga, mesmo oriundo do oriente, instalou-se na Galiza dedicando sua vida para a cristianização de pagãos e hereges. Sua atuação continuamente buscou consolidar a fé cristã frente a qualquer manifestação religiosa distinta da ortodoxia da Igreja. Do ponto de vista ideológico, é possível que o Bracarense tenha sido visto como um continuador da obra de Santiago, ${ }^{\infty} 0$ apóstolo evangelizador da Hispânia, considerado o patrono de toda a Península Ibérica. No século VIII, 0 sepulcro deste apóstolo fora descoberto na mesma região onde o Bracarense atuara como evangelizador. Desta forma, assim como Santiago, Martinho de Braga era um importante líder cristão que deveria ser lembrado, no século X, como uma antítese de Maomé e seus principais seguidores.

Em oposição às Sunnas e Hadiths islâmicos, fazia-se necessário a preservação, a leitura e o estudo de textos cristãos ibéricos. Ao escolher dentre vários textos e optar por uma obra de Martinho de Braga, Jimeno, o copista, e seus companheiros estavam cientes da importância de manter vivo o passado cristão hispânico como um elemento aglutinador e motivador dos monges emilianenses, que viviam sujeitos às aceifas muçulmanas devido à região onde estava localizado o Mosteiro de San Millán de la Cogolla.

O cenóbio emilianense, a despeito de suas inúmeras funções estratégicas, possuía também um importante papel social e econômico para a região riojana. A grandeza dos mosteiros fundados por Martinho de Braga certamente não escapou ao conhecimento dos monges emilianenses. A esse respeito sabemos, inclusive, a partir de documentos apresentados em 656 no X Concílio de Toledo," que o mosteiro de Dume possuia mais de 500 escravos, ${ }^{n}$ o que naturalmente retrata a sua

( Tal afirmativa não significa, contudo, que acreditemos ter o referido apóstolo estado na Península. Na verdade, tal possibilidade já demonstrou-se praticamente impossivel: Cf.: SOTOMAYOR Y MURO, Manuel. La Iglesia en la España Romana. In: GARCIA-VILLOSLADA, Ricardo. (Dir.) op. cit., T. 1. v. 1. p. 150-156.

* Lembremos que os monges emilianenses conheciam o conteúdo das atas conciliares, visto que em sua biblioteca, como já mencionamos, estivera presente a obra organizada por Isidoro de Sevilha, intitulada como Collectio Hispania.

a Cf: Concilios Visigóticos e Hispano-Romanos. Edición Jose Vives. Madrid: CSIC. Instituto Enrique Florez, 1963. p. 323. 
considerável prosperidade. Logo, a lembrança, a partir da reprodução de uma obra, daquele que conseguira lançar as bases de um forte, amplo e rico movimento monástico na Galiza, apresentava-se como algo muito provável.

Nestes mosteiros, evidentemente, o desenvolvimento e incentivo da vida espiritual era o principal objetivo. Como centro de vida monástica, onde vivia-se sob os princípios de uma regra e sob a inspiração de textos voltados para incrementar a espiritualidade, as reflexões e ensinamentos do bracarense quanto a uma forma de vida honesta eram de grande importância para todos aqueles que aspiravam a vita vera angelica. Não é de nos admirar, portanto, que junto ao texto do bispo de Braga, fossem copiadas outras obras com nítido caráter de espiritualidade monástica.

Martinho de Braga, como já assinalamos, foi uma figura chave no processo de reorganização da igreja sueva. Seus escritos, mesmo enfatizando aspectos diferenciados da vida cristã, tinham como objetivo primordial o ordenamento e o fortalecimento da igreja. Esta, após mais de um século de existência em um reino cuja autoridade política adotara práticas religiosas distintas do Catolicismo, tivera que, tão logo lhe foi possivel, promover uma melhor preparação dos seus quadros internos. Em outras palavras, os clérigos galaicos não só haviam se afastado da ortodoxia, como também pareciam desconsiderar aspectos básicos relacionados à hierarquização, conhecimento da liturgia e, principalmente, careciam de formação intelectual adequada para a prática pastoral.

No século X, também a igreja riojana encontrava-se em reorganização e padecia dos mesmos problemas da Igreja Galaica no período suevo. Após séculos de controle muçulmano, as terras reconquistadas passaram a ser alvo da formação de paróquias, fundação e construção de mosteiros e igrejas e da reorganização episcopal. Concilios foram realizados a fim de detectar e corrigir problemas. Neste contexto, onde os monges tinham papel predominante na liderança eclesiástica, ${ }^{\circ}$ fazia-se fundamental meditar sobre o passado cristão peninsular, no qual Martinho de Braga exerceu um relevante papel, bem como sobre suas obras escritas no século VI, que respondessem às preocupações similares às da igreja riojana do século $\mathrm{X}$.

Há que se lembrar, ainda, que o tipo de monacato adotado e desenvolvido por Martinho possuía afinidade com a proposta beneditina. Como sabemos, segundo tal modelo, a importância conferida aos estudos apresenta-se como algo a ser ressaltado. Não é por acaso que os historiadores," de maneira geral, destacam a importância dos mosteiros da Galiza, fundados por Martinho, como centros de difusão da cultura clássica e cristã. Considerando a necessidade de melhor preparação dos clérigos galaicos, bem como dos riojanos que adotaram a regra beneditina, no século X, podemos compreender, não apenas a identificação entre Martinho de Braga e Säo Bento, mas, igualmente, a afinidade destes com a vida monástica exercitada em San Millán de la Cogolla. Assim, neste momento de reorganização da igreja riojana, em oposição ao esplendor intelectual do califado de

* O mosteiro de San Millán de la Cogolla não só funcionou como sede do governo episcopal como também muitos de seus monges chegaram a ocupar a cargo episcopal.

m

Cf.: nota 20. 
Córdova, que seduzia a muitos cristãos, fazia-se necessánio constituir centros de difusão intelectual e espiritual do cristianismo, como foram os antigos mosteiros galaicos.

Finalmente, devemos destacar, mais uma vez, que a obra Formulae Vitae Honestae fora dedicada ao rei suevo, Miro, sendo considerada um Espelho de Principes. Esta obra apresentava diretrizes morais para vida de qualquer pessoa, religiosa ou não, mas, sobretudo, delineava um modelo ideal de rei cristão. Ou seja, fornecia ao monarca elementos para uma conduta em consonância com os princípios eclesiásticos. Dessa forma, a presença desse escrito na biblioteca emilianense pode também estar relacionada a questões de caráter político.

Considerando a relação acima assinalada, vejamos: La Rioja era o centro mais importante do Reino de Pamplona, já que uma das cidades riojanas, Nájera, tornara-se residência real. O Reino de Pamplona, como já mencionamos, foi constituindo-se no século IX e só figura como reino organizado no início do século X. Nesse sentido, tratava-se de uma monarquia nascente, ainda em processo de consolidação. O mosteiro de La Rioja estava situado próximo a Nájera, sendo visitado periodicamente pelo rei pamplonês e sua corte, que nessas ocasiões agraciava o cenóbio com ricas doações. ${ }^{\text {" }}$ Logo, por que não possuir, no acervo da biblioteca, obras que tinham como objetivo primeiro apresentar conselhos cristãos aos governantes? Ou ainda, por que não dispor de obras nas quais os próprios clérigos que residiam em San Millán de la Cogolla e ocupavam um papel de destaque como conselheiros reais, poderiam inspirar-se para instruir aos reis?

Frente ao apresentado, pudemos perceber a semelhança existente entre o contexto histórico no qual viveu Martinho de Braga e aquele do século X, caracterizado pela expansão e consolidação do monacato riojano. Embora, evidentemente, as especificidades e singularidades históncas de cada período não possam ser desprezadas, há sem dúvida, pontos de contatos entre esses dois momentos. Assim, acreditamos que a retomada de um determinado autor, mesmo séculos depois, explica-se em geral pela familiaridade das temáticas por ele abordadas. Insistimos, pois, que toda obra literária apresenta, em potencial, várias possibilidades de leitura que podem explicar e justificar o renovado interesse por sua recepção e leitura, mesmo em contextos históricos diferentes.

Dessa forma, ao concluirmos, podemos compreender por que dentre os inúmeros autores presentes nas bibliotecas pirenaicas, os monges emilianenses teriam, no século $\mathrm{X}$, demonstrado interesse e copiado a obra de um autor, naquele momento, quase desconhecido, como Martinho de Braga, cuja produção desenvolvera no século VI.

*5 A titulo de flustração, devemos lembrar que também os monarcas suevos fizeram doações à Igreja Sueva para a construção de mosteiros. Cf.: ALTANER, Berthold. Patrologia. 3.ed. Madrid: Espasa Calpe, 1955. p. 25; FERNÁNDEZ ALONSO, Justo. Martino, vescovo di Dume. op. cit., p. 1230-1232. p. 1230; PRIETO PRIETO, A. El Marco Político Religioso de los Concilios Bracarenses I y II. In: $O$ Concilio de Braga e a Função da Legislaçảo Particular da Igreja. Atas da XIV Semana Internacional de Direito Canônico. Braga: 1975. p. 33-91, p. 78. 